\title{
Comparison of the effects of intraocular irrigating solutions on the corneal endothelium in intraocular lens implantation
}

\author{
Mamoru Matsuda, Shigeru Kinoshita, Yuichi Ohashi, Yoshikazu Shimomura, Nobuyuki \\ Ohguro, Hitoshi Okamoto, Tatsuya Omoto, Hisashi Hosotani, Hirotoshi Yoshida
}

\begin{abstract}
We conducted a randomised prospective controlled study to determine the effects of a glucose glutathione bicarbonate solution (BSS Plus) and a citrate acetate bicarbonate solution (S-MA $)$ on the corneal endothelium in patients undergoing extracapsular cataract extraction with posterior chamber lens implantation. One eye of each patient was randomly assigned to receive BSS Plus, and the other eye to receive S-MA2. BSS Plus caused significantly less corneal swelling on the first postoperative day than did S-MA2. There was no difference between the two solutions in their effect on corneal thickness one week and one month postoperatively. Computer assisted morphometric analysis of wide-field specular microscopic photographs demonstrated minimal changes in endothelial morphological characteristics in the eyes irrigated with BSS Plus. By comparison S-MA $\mathrm{MA}_{2}$, caused a significant loss of endothelial cells and a marked reduction in the figure coefficient. These results indicated that BSS Plus has a clinical advantage over S-MA with respect to the corneal endothelium.
\end{abstract}

With the development of sophisticated intraocular surgical techniques, there is an increasing need for commercially available intraocular irrigating solutions that can maintain the integrity of the corneal endothelium and other intraocular tissues even when used in a large volume and for a long time period. Previous in-vitro perfusion studies have shown that normal saline, Plasmalyte 148, lactated Ringer's solution, and balanced salt solution (BSS) are toxic to the corneal endothelium. ${ }^{12}$ These studies have also shown that maintenance of endothelial integrity can best be obtained by use of glutathione bicarbonate Ringer's solution (GBR), which is similar in chemical composition to that of aqueous humour. ${ }^{1-4}$ However, GBR is not suitable for clinical use, since it is chemically unstable once made up.

Two intraocular irrigating solutions have recently become commercially available (Table 1). They are BSS Plus, ${ }^{5}$ a glucose glutathione bicarbonate solution, and $\mathrm{S}-\mathrm{MA}_{2}{ }^{67}$ a citrate acetate bicarbonate solution. BSS Plus is similar to GBR except for lacking adenosine and having an addition of oxidised glutathione instead of reduced glutathione. $\mathrm{S}-\mathrm{MA}_{2}$ is also similar to GBR except that citrate and acetate are added, and glutathione and adenosine are lacking from the medium. Previous experimental studies ${ }^{s-8}$ and clinical trials ${ }^{9-12}$ have demonstrated that both solutions are more effective in preventing corneal swelling and maintaining the structure of the corneal endothelium than either lactated Ringer's solution or BSS.

Which irrigating solution, BSS Plus or S$\mathrm{MA}_{2}$, is better for the corneal endothelium is of great importance. Recent experimental studies on rabbit, cat, and human donor corneas have consistently shown that S-MA $\mathrm{A}_{2}$ may be more harmful to the endothelium than BSS Plus. ${ }^{1314}$ Consequently this randomised prospective controlled study was undertaken to determine whether there is a difference between BSS Plus and S-MA $\mathrm{MA}_{2}$ concerning the effects on the corneal endothelium in patients undergoing posterior chamber lens implantation.

\section{Materials and methods}

We studied 21 patients with senile cataract scheduled for extracapsular cataract extraction with posterior chamber lens implantation. The age of the patients ranged from 58 to 88 years (mean, 74 years). Informed written consent was obtained from each patient. Both eyes of each patient were operated on by one surgeon with the same technique and medications. The operations were performed at one-week intervals. One eye of each patient was randomly assigned to receive BSS Plus and the other eye to receive S-MA

A complete ocular examination was performed on all patients. We excluded patients with a history of ocular trauma, surgery, or contact lens wear. Patients with systemic disease, such as diabetes and cystic fibrosis, or ocular conditions that might affect the corneal endothelium, such as uveitis, pseudoexfoliation syndrome, and glaucoma, were also excluded, as were patients with low cell densities or morphological abnormalities of the endothelium preoperatively. Only

\begin{tabular}{|c|c|c|c|}
\hline Constituent & $G B R$ & BSS Plus & $S-M A_{2}$ \\
\hline $\begin{array}{l}\text { Sodium chloride } \\
\text { Potassium chloride } \\
\text { Calcium chloride } \\
\text { Magnesium chloride } \\
\text { Magnesium sulphate } \\
\text { Sodium acetate } \\
\text { Sodium citrate } \\
\text { Sodium acid phosphate } \\
\text { Disodium phosphate } \\
\text { Sodium bicarbonate } \\
\text { Dextrose } \\
\text { Glutathione (reduced) } \\
\text { Glutathione (oxidised) } \\
\text { Adenosine } \\
\text { pH } \\
\text { Osmolarity (mOsm) }\end{array}$ & $\begin{array}{c}111.6 \\
4.8 \\
1.1 \\
0.78 \\
- \\
- \\
- \\
\\
-\quad 0.86 \\
-\quad \\
29 \cdot 2 \\
5.01 \\
0.30 \\
- \\
0.50 \\
7.4 \\
274\end{array}$ & $\begin{array}{l}122 \cdot 2 \\
5 \cdot 08 \\
1.05 \\
0.98 \\
- \\
- \\
- \\
-\quad \\
3 \cdot 0 \\
25 \cdot 0 \\
5 \cdot 11 \\
-\quad 0.30 \\
-\quad 7 \cdot 4 \\
305\end{array}$ & $\begin{array}{r}112 \cdot 9 \\
4 \cdot 8 \\
1 \cdot 2 \\
-\quad 1 \cdot 2 \\
4 \cdot 4 \\
3 \cdot 4 \\
-\quad \\
-\quad 25 \cdot 0 \\
-8 \cdot 3 \\
- \\
- \\
-7 \cdot 3 \\
290\end{array}$ \\
\hline
\end{tabular}

All concentrations expressed in $\mathrm{mmol} / \mathrm{l}$ of solution. 
patients with neither surgical nor postoperative complications were included in the study.

A standard surgical technique was used on all patients. We made a fornix-based conjunctival flap and limbal incision of a $10 \mathrm{~mm}$ arc length and filled the anterior chamber with $1 \%$ sodium hyaluronate. After anterior capsulotomy with a bent 23 gauge needle the lens nucleus was expressed by a two-point compression without collapse of the corneal dome. We then performed a cortical clean-up with an aspiration-irrigation instrument, followed by expansion of the capsular bag with $1 \%$ sodium hyaluronate, insertion of posterior chamber lens in the capsular bag, and aspiration of the viscoelastic substance. The wound was closed with five to seven interrupted 10-0 nylon sutures. No epinephrine was added to the irrigating solutions or injected into the anterior chamber. At the end of surgery 0.1 to $0.6 \mathrm{ml}$ of acetylcholine chloride was injected into the anterior chamber. Postoperative medications, including topical antibiotics and corticosteroids, were given in the same fashion to all patients.

Central corneal thickness was measured preoperatively and at one day, one week, and one month after surgery. A Haag-Streit slit-lamp with a pachymeter fitted with central fixation lights, according to Mishima and Hedbys, ${ }^{15}$ is used for these measurements. The use of these fixation lights is essential in order to obtain consistent measurements of central thickness. Each time the average of three consecutive readings was recorded. The endothelium of the central cornea ( 3 to $4 \mathrm{~mm}$ in diameter) was also photographed with a wide-field specular microscope preoperatively and at one week and one month after the operation. Specular microscopy during the first postoperative week was not performed in order to keep the eyes as sterile as possible.

Approximately 10 to 15 photographs were taken of each cornea. Adequate photographs were obtained from each eye of the 21 patients at all examinations. The photographs with good resolution were used for analysis. A total of 100 adjacent cells were analysed with a computerised digitiser, as previously described. ${ }^{16} 17$ Corneal pachymetry, endothelial photography, and morphological evaluation were performed by independent examiners who were unaware of which irrigating solution was used for any eye until the entire study was completed.

Endothelial cell density (cells $/ \mathrm{mm}^{2}$ ) was calculated by dividing $10^{6}$ by the mean cell area. Cell loss was expressed as a percentage of the preoperative cell density. The coefficient of variation in cell size (SD expressed as a ratio to the mean cell area) was used as a quantitative measurement of cell size variability (polymegethism). Cell shape was defined by the number of apices of each cell. The percentage of hexagonal cells was used to describe cell shape variability (pleomorphism). The figure coefficient was also calculated by the formula of $4 \pi \mathrm{A} / \mathrm{P}^{2}$, where $A$ is the cell area and $P$ is the total perimeter. This factor is a dimensionless index describing the degree to which a cell approximates to a circle. The value of this index is 1.0 for a perfect circle and 0.907 for a perfect hexagon.
Table 2 Clinical data and preoperative endothelial morphology: mean (SEM)

\begin{tabular}{|c|c|c|}
\hline & $\begin{array}{l}\text { BSS Plus group } \\
(n=21)\end{array}$ & $\begin{array}{l}S-M A_{2} \text { group } \\
(n=21: \text { paired } \\
\text { eyes })\end{array}$ \\
\hline $\begin{array}{l}\text { Irrigation time }(\mathrm{min}) \\
\text { Infusion volume }(\mathrm{ml}) \\
\text { Corneal thickness }(\mathrm{mm})\end{array}$ & $\begin{array}{l}8.9(1 \cdot 0) \\
97 \cdot 1(12 \cdot 8) \\
0.53(0.008)\end{array}$ & $\begin{array}{l}10.0(1 \cdot 7) \\
97.4(12 \cdot 1) \\
0.53(0.008)\end{array}$ \\
\hline $\begin{array}{l}\text { Endothelial morphology } \\
\text { Cell density (cells } / \mathrm{mm}^{2} \text { ) } \\
\text { Coefficient of variation }\end{array}$ & $\begin{array}{c}2900(89) \\
0.330: 0.298 \\
0.390 \\
58.3(1.7)\end{array}$ & $\begin{array}{c}2961(125) \\
0.314: 0 \cdot 276, \\
0 \cdot 348 \\
61 \cdot 0(1 \cdot 7)\end{array}$ \\
\hline Figure coefficient & $0.850(0.002)$ & $0.852(0.002)$ \\
\hline
\end{tabular}

${ }^{\star}$ Median: quartile.

The figure coefficient was used to quantify the degree to which the endothelial monolayer deviates from its normal hexagonal patterns.

Differences were considered statistically significant if parametric (two-tailed paired $t$ test) and non-parametric (two-tailed Wilcoxon onesample test) tests yielded a $p$ value of less than $0 \cdot 05$.

\section{Results}

There were no significant differences in amount of irrigating solution or irrigation time between the eyes receiving BSS Plus and those receiving $\mathrm{S}-\mathrm{MA}_{2}$ (Table 2). These two groups were also equivalent with respect to all the baseline variables, including corneal thickness, endothelial cell density, coefficient of variation in cell size, percentage of hexagonal cells, and figure coefficient.

In both the BSS Plus and S-MA 2 groups the corneal thickness increased significantly over the baseline values one day after surgery and steadily decreased with time (Fig 1). The corneal thickness on day 1 was significantly greater in the $S$ $\mathrm{MA}_{2}$ group than in the BSS Plus group. There was no significant difference in corneal thickness between the two groups one week and one month after surgery. One month postoperatively, the corneal thickness returned to the baseline values in the BSS Plus group, while it was significantly increased from the preoperative value in the $S$ $\mathrm{MA}_{2}$ group.

The eyes receiving $S-M A_{2}$ had a significant endothelial cell loss from the baseline one week and one month after surgery, whereas those with BSS Plus did not (Fig 2). The mean cell losses were higher for the S-MA 2 group than for the BSS Plus group at any point in time, though this difference was statistically insignificant. The coefficient of variation in cell size and percentage of hexagonal cells remained unchanged from the baseline values in both groups: The $\mathrm{S}-\mathrm{MA}_{2}$ group demonstrated a significant decrease in the figure coefficent compared with the baseline value and with the BSS Plus group one month after surgery. No change in the figure coefficient was noted in the BSS Plus group.

\section{Discussion}

The results of this randomised prospective controlled study demonstrated that BSS Plus offers a significant clinical advantage over S-MA with respect to the corneal endothelium in 


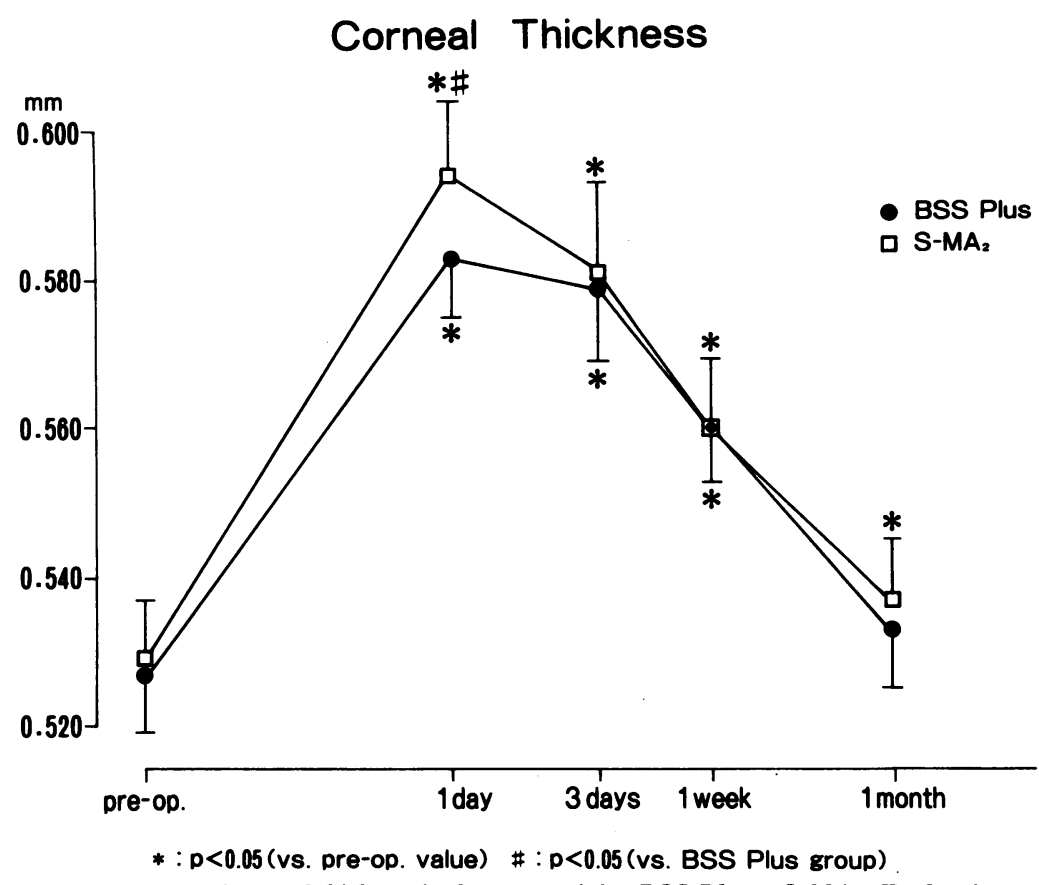

Figure 1 Central corneal thickness in the eyes receiving BSS Plus or S-MA $A_{2}$ Each point represents the mean; bars represent SEM. ${ }^{\star}$ Significantly different $(p<0.05)$ from the baseline value. \#Significantly different $(p<0.05)$ compared with the BSS Plus group.

patients undergoing extracapsular cataract extraction with posterior chamber lens implantation. The eyes receiving BSS Plus had less corneal swelling and fewer endothelial morphological changes than the paired eyes receiving S-MA2.

Araie $^{13}$ recently showed that $\mathrm{S}-\mathrm{MA} \mathrm{A}_{2}$ perfusion substantially increased the permeability of carboxyfluorescein to the rabbit corneal endothelium, while BSS Plus did not. In an in- vitro perfusion of human donor corneas Edelhauser ${ }^{14}$ has also noted that S-MA 2 caused more corneal swelling than BSS Plus and a marked breakdown of the endothelial cell junctions, which is similar to what occurs in calcium-free medium, ${ }^{121819}$ whereas BSS Plus maintained the functional and structural integrity of the endothelium. These observations suggest that a significantly greater corneal thickness noted in our patients with S-MA2 one day after surgery may be due at least in part to compromised endothelial barrier function.

In our study none of the morphological parameters changed significantly from the baseline values in the eyes receiving BSS Plus. By comparison a significant cell loss from the baseline was noted in the paired eyes receiving $S$ $M A_{2}$. The S-MA $-\mathrm{A}_{2}$ group also showed a marked decrease in the figure coefficient one month after surgery, indicating a loss of the normal hexagonal pattern. However, no significant change was noted in the coefficient of variation in cell size (polymegethism) or percentage of hexagonal cells (pleomorphism). A recent study has also demonstrated that in-vivo irrigation of the anterior chamber in cats with S-MA ${ }_{2}$ caused marked endothelial morphological changes (polymegethism and pleomorphism), while BSS Plus did not. ${ }^{14}$ These endothelial changes were found to be present during the early postoperative period and to resolve within one week after the irrigation. Since we took the first endothelial photographs one week after surgery, significant increases in polymegethism and pleomorphism caused by $S-M A_{2}$ might not have been detectable.

The normal corneal endothelium is a densely packed monolayer with a regular hexagonal pattern. A regular hexagonal shape (given a
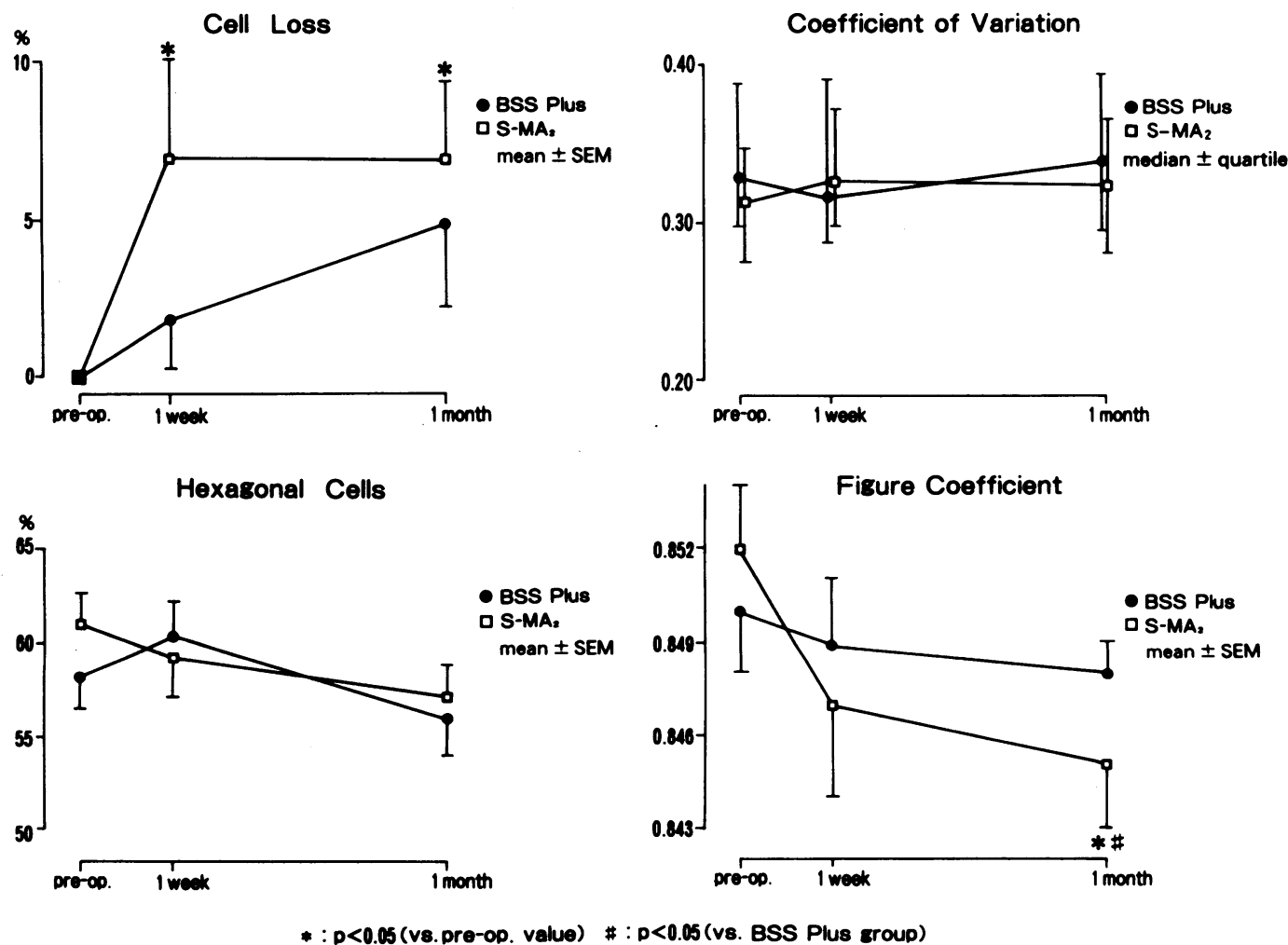

*: $p<0.05$ (v8.pre-op. value) \#: $p<0.05$ (v8. BSS Plus group)

Figure 2 Endothelial cell loss (top left), coefficient of variation in cell size (top right), percentage of hexagonal cells (bottom left)

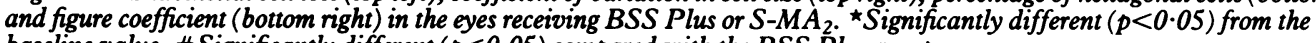
baseline value. \#Significantly different $(p<0.05)$ compared with the BSS Plus group. 
constant area) is the most geometrically or thermodynamically stable configuration to cover a plane, ${ }^{20-22}$ because this shape will keep the total perimeter at a minimum, and thus produce the minimum surface tension energy. Therefore it can be proposed that a marked disruption of regular hexagonal pattern noted after $\mathrm{S}-\mathrm{MA}_{2}$ irrigation represents an endothelium in a physically unstable state, ${ }^{162}$ which may be more susceptible to additional trauma. Morever, a loss of regular hexagonal pattern may reflect cell loss, causing adjacent cells to assume irregular hexagonal or elongated shapes (given a constant area) to cover the cell free area. ${ }^{163}$

The difference between BSS Plus and S-MA2 is that $\mathrm{S}-\mathrm{MA}_{2}$ lacks glutathione and contains sodium acetate and citrate. Oxidised or reduced glutathione, which are present in the aqueous humour ${ }^{24}$ and corneal endothelium, ${ }^{25}$ have been shown to be important for the maintenance of endothelial cell junctions and barrier function. ${ }^{13426-28}$ Since acetate and citrate are unnatural buffers to the intraocular tissues, they may have some adverse effects on the endothelium. ${ }^{1314}$ In addition there is a possibility ${ }^{1314}$ that citrate may chelate calcium in the solution and decrease an amount of free $\mathrm{Ca}^{2+}$, which is essential for maintaining endothelial junctional complexes and barrier function. ${ }^{121819}$ Therefore the lack of glutathione, presence of acetate and citrate, and possible loss of free $\mathrm{Ca}^{2+}$ in $\mathrm{S}-\mathrm{MA}_{2}$ may all be responsible for the endothelial alterations observed in both previous experimental investigations ${ }^{13}{ }^{14}$ and the present clinical study.

Our results indicated that BSS Plus is more effective in protecting the functional and structural integrity of the corneal endothelium than $\mathrm{S}-\mathrm{MA}_{2}$ in patients undergoing posterior chamber lens implantation. The ability of BSS Plus to maintain endothelial integrity can be attributed to its chemical similarity to aqueous humour. Patients with low cell densities or morphological abnormalites of the endothelium have been shown to be more susceptible to surgical trauma and to a variety of stresses. ${ }^{169-33}$ The use of BSS Plus may be preferable and safer in this group of high-risk patients.

Grateful acknowledgement is made to Dr S Komemushi for his part as a controller and to $\operatorname{Dr} M$ Inaba for collaboration in photographic analysis.

This study was supported in part by a research grant from the Osaka Eye Bank, Osaka, Japan.

1 Edelhauser HF, Van Horn DL, Hyndiuk RA, Schultz RO. Intraocular irrigating solutions; their effect on the corneal endothelium. Arch Ophthalmol 1975; 93: 648-57.

2 Edelhauser'HF, Van Horn DL, Schultz RO, Hyndiuk RA. Comparative toxicity of intraocular irrigating solutions on the corneal endothelium. Am $\mathcal{F}$ Ophthalmol 1976; 81: 473the 81 .

3 Dikstein S, Maurice DM. The metabolic basis to the fluid pump in the cornea. F Physiol (Lond) 1972; 221: $29-41$

4 McCarely BE, Edelhauser HF, Van Horn DL. Functional and structural changes in the corneal endothelium during in vitro perfusion. Invest Ophthalmol Vis Sci 1973; 12:410-7.

5 Edelhauser HF, Gonnering R, Van Horn DL. Intraocular irrigating solutions: a comparative study of BSS Plus and lactated Ringer's solution. Arch Ophthalmol 1978; 96: 51620.

6 Otori T, Hohki T, Yamamoto Y, Yamamoto M, Ikeda M Physiological studies on the intraocular irrigating solution fo ophthalmic surgery: a preliminary study. Nippon Ganko Gakkai Zasshi 1980; 84: 1272-7.

7 Otori T, Nakao Y, Mano T, Haruta Y, Ikeda M. Studies on the intraocular irrigating solutions for ophthalmic surgery: report 3: Reappraisal of the role of bicarbonate and clinical use of S-MA2. Nippon Ganka Gakkai Zasshi 1983; 87: 96873 .

8 Glasser DB, Matsuda M, Ellis JG, Edelhauser HF. Effects of intraocular irrigating solutions on the corneal endothelium after in vivo anterior chamber irrigation. Am f Ophthalmol 1985; 99: 321-8.

9 Benson WE, Daimond JG, Tasman W. Intraocular irrigating solutions for pars plana vitrectomy: a prospective, randomised, double-blinded study. Arch Ophthalmol 1981; 99: 1013-5.

10 Kline O, Symes DJ, Lorenzetti OJ, deFaller JM. Effect of BSS Plus on the corneal endothelium with intraocular lens implantation. F Toxicol-Cutan Ocul Toxicol 1984; 2: 243-7.

11 Matsuda $M$, Tano $Y$, Inaba $M$, Sato $M$, Inoue $Y$, Manabe $\dot{R}$. Corneal complications after pars plana vitrectomy using $\mathrm{S}$ $\mathrm{Ma}_{2}$ for an intraocular irrigating solution. Folia Ophthalmol $\mathrm{Ma}_{2}$ for an intraocular
fpn 1983; 34: 1424-8.

Jpn 1983; 34: 1424-8.
12 Matsuda M, Tano Y, Edelhauser HF. Comparison of intraocular irrigating solutions used for pars plana vitrectomy and prevention of endothelial cell loss. Fpn f Ophthalmol 1984 28: $230-8$.

13 Araie M. Barrier function of corneal endothelium and the intraocular irrigating solutions. Arch Ophthalmol 1986; 104: 435-8.

14 Edelhauser HF. Intraocular irrigating solutions. In: Lamberts DW, Potter DE, eds. Clinical ocular pharmacology. Boston Toronto: Little, Brown, 1987: 431-44.

15 Mishima S, Hedbys BO. Measurement of corneal thickness with Haag-Streit pachymeter. Arch Ophthalmol 1968; 80: 710-3.

16 Schultz RO, Matsuda M, Yee RW, Edelhauser HF, Schultz KJ. Corneal endothelial changes in type I and type II $\mathrm{KJ}$. Corneal endothelial changes in type I and type
diabetes mellitus. Am $\mathcal{F}$ Ophthalmol 1984; 98: 401-10.

17 Yee RW, Matsuda M, Schultz RO, Edelhauser HF. Changes in the normal corneal endothelial cellular pattern as a function of age. Curr Eye Res 1985; 6: 671-8.

18 Kaye GI, Mishima S, Cole JD, Kaye NW. Studies on the cornea VII. Effects of perfusion with a Ca+ free medium on the corneal endothelium. Invest Ophthalmol Vis Sci 1968; 7 53-6.

19 Stern ME, Edelhauser HF, Pederson HJ, Staatz WD. Effects of ionophores X537A and A23187 and calcium-free medium on corneal endothelial morphology. Invest Ophthalmol Vis Sci 1981; 20: 497-507.

20 Honda H. Geometrical models for cells in tissue. Int Rev Cytol

21 Tanimura K. A quantitative analysis of corneal endothelial cells. Folia Ophthalmol F pn 1981; 32: 1835-9.

22 Bonner JT. The forms of tissues, or cell aggregates. In: Bonner JT, Thomspon DW, eds. On growth and form. London: Cambridge University Press, 1969; 88-119.

23 Matsuda M, Suda T, Manabe R. Quantitative analysis of endothelial mosaic pattern changes in anterior keratoconus. Am $\mathcal{F}$ Ophthalmol 1984; 98: 43-9.

24 Riley MV, Meyer RF, Yates EM. Glutathione in the aqueous humor of human and other species. Invest Ophthalmol Vis Sci 1980; 19: 94-6.

25 Riley MV, Yates EM. Glutathione in the epithelium and endothelium of bovine and rabbit cornea. Exp Eye Res 1977; 25: 385-9.

26 Whikehart DR, Edelhauser HF. Glutathione in rabbit corneal endothelia: the effects of selected perfusion fluids. Invest endothelia: the effects of selected perf
Ophthalmol Vis Sci 1978; 17: 455-64.

27 Edelhauser HF, Van Horn DL, Miller T, Pederson HJ. Effect of thioloxidation of glutathione with diamide on corneal endothelial function, junctional complexes, and microfilaments. F Cell Biol 1976; 68: 567-78.

28 Araie M, Shirasawa E, Hikita M. Effect of oxidized glutathione on the barrier function of the corneal endothelium. Invest Ophthalmol Vis Sci 1988; 29: 1884-7.

29 Bourne WM, Brubaker RF, O'Fallon WM. Use of air to decrease endothelial cell loss during intraocular lens implantation. Arch Ophthalmol 1979; 97: 1473-5.

30 Rao GN, Shaw EL, Arthur EJ, Aquavella JV. Endothelial morphology and corneal detergescence. Am Ophthalmol morphology and

31 Rao GN, Aquavella JV, Goldberg SH, Berk SL. Pseudophakic bullous keratopathy: relationship to preoperative corneal bullous keratopathy: relationship to preoperative cort
endothelial status. Ophthalmology 1984; $91: 1135-47$.

32 Sweeney DF, Holden BA, Vannas A, et al. The clinical significance of corneal endothelial polymegethism. Invest Ophthalmol Vis Sci 1985; 26 (suppl): 53.

33 O'Neal MR, Polse KA. Decreased endothelial pump function with aging. Invest Ophthalmol Vis Sci 1986; 27: 457-63. 